\title{
MODEL FOR DETERMINATION THE CONTRIBUTION OF ADVERSE EVENTS DURING DYNAMIC MEASUREMENT OF ROAD MARKING RETROREFLECTION
}

\author{
Darko Babić ${ }^{1}$, Dario Babić ${ }^{2}$, Mario Fiolić ${ }^{3}$, Davor Krasić ${ }^{4}$ \\ 1,2,3 Faculty of Transport and Traffic Science, University of Zagreb, Croatia \\ ${ }^{4}$ Institute for Tourism, Zagreb, Croatia
}

Received 18 January 2019; accepted 9 April 2019

\begin{abstract}
Retroreflection of road markings should be periodically tested to ensure they are adequately visible to drivers. Dynamic testing of retroreflection using a vehicle-mounted reflectometer offers numerous advantages over static testing, but the overall evaluation of the markings quality, based on its results, may be incorrect due to the influence of various adverse events. These events include the presence of road works, dirt or humidity on the markings, overtaking of a slow vehicle, curves and intersections and the absence of markings. Here we present a model that estimates the contribution that such adverse events make to the total dynamic measurement. We developed the model using a dataset of 912 dynamic measurements collected over a 4-year period on state roads across 20 counties in Croatia, and we validated the final model on an independent set of 80 measurements. The results suggest that this tool may help road authorities to accurately evaluate the results of dynamic measurement and thus quality of the road marking.
\end{abstract}

Keywords: road markings, retroreflection, dynamic measurements, road asset management, road safety, quality testing.

\section{Introduction}

Road markings provide drivers with essential route and safety information. These markings contribute significantly to traffic safety, in part because they occupy the driver's central field of view. In fact, the presence of central and edge markings on their own may reduce the total number of traffic accidents by 20\% (Miller, 1992). Road markings are only as effective as they are visible to drivers, which highlights the importance of selecting marking materials that provide adequate retroreflection over a sufficiently long service life. Since the choice of marking materials depends on other factors as well, including durability and cost (Cuelho et al., 2003), retroreflection must be regularly assessed to ensure adequate visibility to drivers.

Quality testing of road markings involves measuring their visibility during the day and at night (Benz et al., 2009), as well as measuring their slip resistance. Visibility can be objectively measured using a retroreflectometer, which is usually done statically as the examiner holds the device in his or her hand. Such static testing may take a long time and disrupt traffic substantially, leading some municipalities to rely on dynamic testing, in which the

${ }^{1}$ Corresponding author: darko.babic@fpz.hr 
retroreflectometer is mounted on a moving vehicle. Although more expensive than static testing, this approach allows the collection of a far larger set of measurements in less time and over a greater surface area of the markings, while causing negligible traffic disruption.

Despite its advantages, dynamic retroreflection measurements may give results which may be rendered less accurate by certain adverse events related to traffic or the environment, such as when the measuring vehicle changes lane to overtake slower vehicles (overtaking), when marking is placed across intersection which causes faster degradation of marking due to the frequent passage of the vehicles (intersection), when markings are no longer present (no marking), when the road curves (curve), when road markings are interrupted by road works (road works), and when at least part of the marking surface is wet (wet marking) or soiled (dirty marking). These events, when occur, affect the measurement of road markings retroreflection and with that may cause incorrect evaluation of their quality. These events have been neglected in the relatively small literature devoted to dynamic retroreflection measurement (e.g. Sitzabee et al., 2013; Dale et al., 2012; Sitzabee et al., 2009).

Therefore, the present study used data collected over a 4-year period across 20 counties of Croatia in order to develop a model for adjusting dynamic retroreflection measurements by taking into account the aforementioned events. The model works by estimating the minimal contribution of such events to the actual measurements.
This is, to our knowledge, the first report of a quantitative method to increase the reliability of dynamic retroreflection measurements, and it may have important implications for road maintenance and policymaking.

\section{Literature Review}

The general belief that prevails in the scientific and professional community dealing with the influence of road markings on road safety is that there is a negative correlation, i.e. that with the presence of the markings and the increase of their retroreflectivity, there is a decrease in the number of traffic accidents during nighttime.

Several studies have proved the positive safety effect of road markings presence on the road safety. In 1981. Federal Highways Administration (Washington DC, USA) concluded that the number of traffic accidents with injured and/or fatalities has decreased significantly (from $3 \%$ to $16 \%$ ) with the presence of middle and/or side lines. "Before and after" study conducted by (Tsyganov et al., 2006) showed that roads without edge marks on the roadway have an $11 \%$ higher risk of traffic accidents compared to the road with edge lines. Also, the presence of edge markers has shown positive effects on traffic safety in nighttime and reduced visibility conditions.

Besides the presence of road markings, their visibility has a significant impact on the driver's behavior and thus road safety especially during low visibility conditions (night, dusk, dawn etc.). Several studies have examined the minimal adequate 
retroflection of road markings to ensure visibility to drivers under dry conditions (Graham et al., 1996; Zwahlen and Schnell, 1997; Loetterle et al., 2000; Parker and Meja, 2003; Debaillon et al., 2007) as well as wet conditions (Gibbons et al., 2012; Gibbons and Hankey, 2007; Gibbons and Williams, 2012). Several studies have explored how retroreflection varies with marking material (Gibbons and Hankey, 2007; Gibbons and Williams, 2012; Zhang et al., 2010), and how the road marking service life changes with different materials and road conditions (Shahata et al., 2008; Zhang et al., 2010; Grosges, 2008; Dale et al., 2012; Sitzabee et al., 2009; Andrady, 1997; Craig et al., 2007). Other studies have explored how drivers adjust their behavior depending on road marking visibility (Zwahlen and Schnell, 2000).

From all above, it is clear that the retroreflection of the road markings should be inspected in order to assure their adequate visibility needed by drivers and thus increase overall road safety. We are aware of only a handful of studies reporting dynamic measurement of road marking retroreflection (Sitzabee et al., 2013; Dale et al., 2012; Sitzabee et al., 2009). These studies were focused on using the mentioned method to collect the data in order to determine the service life of road markings. Although the authors in mentioned studies used dynamic method they didn't analyze the impact of various events on the quality of measurement results and overall evaluation of markings quality which is crucial for planning the maintenance activities. Therefore, the present study derived a model for assessing the minimal contribution (length) of adverse events to the total road length measured.

\section{Methodology}

\subsection{Retroflection Definition and Dynamic Measurement}

Retroreflection coefficient or nighttime visibility $(R L)$ is defined as the ratio of the output surface luminance $(L)$ to the input surface illuminance (E) (EN 1436:2009):

$R_{L}=\frac{L}{E}$

where $R_{L}$ usually has the units of millicandela per lux per square meter $\left(\mathrm{mcd} / \mathrm{lx} / \mathrm{m}^{2}\right) . R_{L}$, in this research, was measured using a ZDR 6020 dynamic retroreflectometer (Zehntner, Sissach, Switzerland) mounted onto the left side of a Mercedes Viano minivan (Fig. 1). The measuring device measures retroreflection according to the EU norm EN 1436:2009, which implies a observation angle of $2.29^{\circ}$, an inlet angle of $1.24^{\circ}$ and a distance of $30 \mathrm{~m}$, while headlights were set to low beam. This testing geometry is identical to that recommended for static retroreflection measurement (EN 1436:2009).

A dataset of 912 measurements of central and edge road markings on state roads in 20 Croatian counties covering a total length of $33,497.87 \mathrm{~km}$ was collected between 2012 and 2015. To ensure the accuracy of the measurement, prior to each measurement the calibration of the device was done according to manufacturer's instructions. Also, as described by Babić et. al., the measurement interval was set to $50 \mathrm{~m}$, which implies that device measures retroreflection every 2 $\mathrm{ms}$ and provides an average value every $50 \mathrm{~m}$. Accuracy of the calibration and the dynamic measurements was checked using a hand-held ZRM 6014 retroreflectometer (Zehntner, Sissach, Switzerland). 


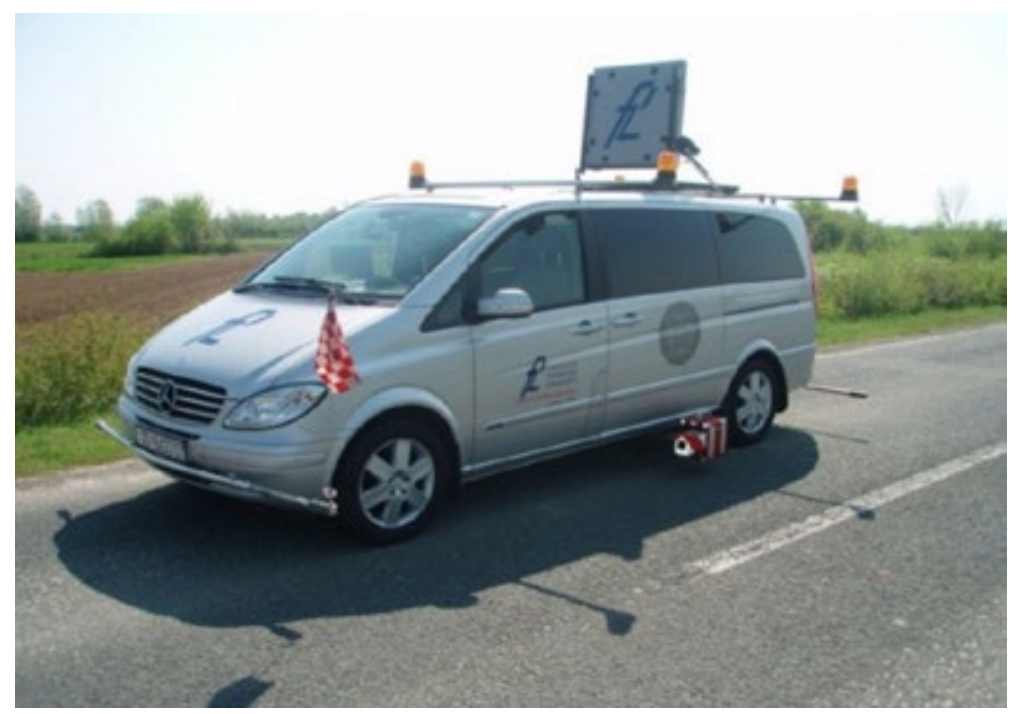

Fig. 1.

Measurement Vehicle Carrying a ZDR 6020 Retroreflectometer Mounted on the Left Side Source: Authors' photo

\subsection{Contribution of Adverse Events to Dynamic Retroreflection Measurements}

For each of the 20 counties, the contribution of dynamic measurements due to the seven adverse events mentioned in section 1 was determined based on visual inspection during the measurement process. In other words, codriver was putting remarks for each event in the measuring software while driving. After the measurement, software exported the total length and percentage share of each event in the whole measurement. These events were selected and defined based on empirical practice by researchers and engineers at the Faculty of Transport and Traffic Sciences in Zagreb and are most common things which may affect the evaluation process of road markings overall.

\subsection{Linear Modelling of the Contribution of Adverse Events to Dynamic Retroreflection Measurements}

Three linear models were generated based on the complete dataset of retroreflection measurements. To generate Model E1, a coefficient $k_{i}$ was calculated for each county $i$ according to the expression:

$k_{i}=\frac{D E_{i}}{\tau_{i}} i \in\{1, \ldots, 20\}$

where DE $i$ refers to the total event length in county $i$ and Ti refers to the total measurement length in that county. The weighted average of $k i$ across all 20 counties was calculated $(0,025395)$ with the weight being the percentage share of $k i$ for each county. This was used to generate the equation: 


$$
E_{1}=0.025395 \cdot M_{D} \pm 0.026857
$$

where $T_{1}$ refers to the minimal event length (in meters), and $M_{D}$ refers to the total measurement length.

By analyzing the share of each event, it has been determined that the event no marking is predominant in relation to other events (the average share of the said event is $33,69 \%$ of the total events). Due to this extreme, that is, large discrepancy with respect to other events in each county, the respective event has been excluded from the analysis in order to obtain a more accurate model (E2). Weighted average of $k i$ in this case is 0.016577 . Final expression of model E2 is:

$$
E_{2}=0.016577 \cdot M_{D} \pm 0.030056
$$

Even though the second model is more accurate, it does not take into account the no marking event which is, as previously mentioned, significantly present in the total share of events. For this reason Model E3 was generated by modifying Model E2 based on the weighted mean of $P_{a}$ which represents the contribution of no marking events in the total measured length:

$$
E_{2}=0.016577 \cdot M_{D} \mid P_{Q}
$$

Since weighted mean of $P_{a}$ in our dataset was found to be 0.498818 , the final optimal model took the form:

$$
E_{3}=0.03323 \cdot M_{D} \pm 0.035551
$$

\section{Results}

Analysis of the entire dataset across all 20 counties showed that the total length of all events was $702875 \mathrm{~m}$, accounting for $2.10 \%$ of the total measured length (absolute deviation, $0.147 \%$ ) (Table 1). The events making up the greatest proportions of the total measured length were no marking $(0.695 \%)$ and road works $(0.595 \%)$.

\section{Table 1}

Lengths of the Seven Adverse Events Affecting Retroreflection and their Contribution to total Measured Length, based on Data from 20 Croatian Counties

\begin{tabular}{|c|c|c|}
\hline Event & Event Length $(\mathbf{m})$ & \% of Total Length \\
\hline Overtaking & $80,500.00$ & 0.240 \\
\hline Intersection & $73,175.00$ & 0.128 \\
\hline No marking & $232,950.00$ & 0.695 \\
\hline Curve & $23,550.00$ & 0.070 \\
\hline Road works & $199,250.00$ & 0.595 \\
\hline Wet marking & $37,600.00$ & 0.112 \\
\hline Dirty marking & $55,850.00$ & 0.167 \\
\hline Total & $\mathbf{7 0 2 , 8 7 5 . 0 0}$ & $\mathbf{2 . 1 0}$ \\
\hline
\end{tabular}

Analysis of the data for each county separately (Table 2 ) showed that there is a significant difference between the length of events in total measurements length in each county from the lowest share in DubrovnikNeretva County (0,010\%) to $3.315 \%$ in SplitDalmatia County. This shows that these events are affected by the road geometry, 
quality of the road surface, maintenance activities etc. Therefore, three linear models were generated in an effort to derive a general method for estimating the minimum content of adverse events in dynamic retroreflection measurements.

\section{Table 2}

Lengths of the Seven Adverse Events Affecting Retroreflection and their Contribution to Total Measured Length, by Croatian County

\begin{tabular}{|c|c|c|c|c|}
\hline County & No. Measurements & $\begin{array}{c}\text { Total } \\
\text { Length }(\mathbf{m})\end{array}$ & Event Length (m) & $\begin{array}{c}\text { Event Length as \% } \\
\text { of Total }\end{array}$ \\
\hline Bjelovar-Bilogora & 31 & $944,950.00$ & $8,500.00$ & 0.899 \\
\hline Brod-Posavina & 17 & $306,050.00$ & $5,200.00$ & 1.699 \\
\hline Dubrovnik-Neretva & 21 & $1,221,950.00$ & $129,600.00$ & 0.010 \\
\hline Istra & 129 & $3,645,950.00$ & $62,350.00$ & 1.710 \\
\hline Karlovac & 52 & $2,276,150.00$ & $20,600.00$ & 0.905 \\
\hline Koprivnica-Križevci & 34 & $1,138,950.00$ & $17,050.00$ & 1.496 \\
\hline Krapina-Zagorje & 39 & $841,200.00$ & $13,400.00$ & 1.593 \\
\hline Lika-Senj & 68 & $3,726,000.00$ & $28,250.00$ & 0.758 \\
\hline Međimurje & 20 & $458,850.00$ & $8,500.00$ & 1.852 \\
\hline Osijek-Baranja & 42 & $1,962,550.00$ & $45,500.00$ & 2.318 \\
\hline Požega-Slavonia & 17 & $467,550.00$ & $9,900.00$ & 2.117 \\
\hline Primorje-Gorski Kotar & 32 & $1,702,550.00$ & $30,450.00$ & 1.788 \\
\hline Šibenik-Knin & 76 & $2,766,100.00$ & $42,600.00$ & 1.540 \\
\hline Sisak-Moslavina & 44 & $1,707,300.00$ & $56,250.00$ & 3.294 \\
\hline Split-Dalmatia & 46 & $2,479,250.00$ & $82,200.00$ & 3.315 \\
\hline Varaždin & 30 & $1,082,600.00$ & $16,850.00$ & 1.556 \\
\hline Virovitica-Podravina & 22 & $1,396,400.00$ & $22,900.00$ & 1.640 \\
\hline Vukovar-Srijem & 35 & $1,298,075.00$ & $38,675.00$ & 2.979 \\
\hline Zadar & 81 & $3,082,050.00$ & $50,900.00$ & 1.651 \\
\hline Zagreb & $\mathbf{9 1 2}$ & $\mathbf{3 3 , 4 9 7 , 8 7 5 . 0 0}$ & $\mathbf{7 0 2 , 8 7 5 . 0 0}$ & $\mathbf{2 . 0 9 8}$ \\
\hline Total/Average & & & & 1.328 \\
\hline
\end{tabular}

In Model E1, data were analyzed on a percounty basis (see coefficients in Appendix 1). The event no marking accounted for $33.7 \%$ of all adverse events in the measurements. Therefore, we generated a potentially less biased Model E2 by removing no marking events from the dataset first. While this gave a more accurate model for our particular dataset, we were concerned that such a model would not be useful in the general case because it completely ignores no marking events. Therefore, we developed Model E3 by adjusting Model E2 based on the weighted mean of the contribution of no marking events to the total measured length. Model E3 was validated against a different dataset of 80 randomly selected dynamic retroreflection measurements carried out on state roads throughout the Croatia. These validation dataset was not previously used for developing a final model (E3) and represent $10.66 \%$ of the dataset used for modeling. For the total measured length of 3,571,550 m, events amounted to $113,027 \mathrm{~m}$, which compares favorably to the value of $118,682.61 \mathrm{~m}$ predicted by Model E3. This discrepancy of $5 \%$ is reasonable and successful. To statistically 
test the difference between measured and modeled length of events we used $t$ test. Before conducting the t test two main assumptions were tested: normality of the data and homogeneity of variances. The normal distribution of data was assumed according to the Central limit theorem. To test the homogeneity of variances we used
$F$ test. The results of $F$ test show that the variances of data are equal (F $1.155>\mathrm{F}$ Critical one-tail 1.451). Therefore, we used a two-sample $t$ test assuming equal variances which indicated no significant difference (Two-tailed P $(T t)$ two-tail > 0.05 ) between the model-predicted event length and the actual event length (Table 3).

Table 3

Statistical Analysis of the Difference Between Adverse Event Length Predicted by Model 3 and Actual Event Length

\begin{tabular}{|c|c|c|}
\hline Measure & Observed & Predicted \\
\hline Mean & 1412.8375 & 1483.532581 \\
\hline Variance & 588935.2517 & 680458.2778 \\
\hline Observations & 80 & 80 \\
\hline Hypothesized mean difference & 0 & \\
\hline degrees of freedom & 158 & \\
\hline$t$ statistic & -0.561223763 & \\
\hline Two-tailed P $(T \leq t)$ two-tail & 0.575440115 & \\
\hline Two-tailed critical $t$ & 1.975092073 & \\
\hline
\end{tabular}

\section{Discussion}

This work represents the first attempt to improve the accuracy of dynamic retroreflection measurements by estimating the minimal contribution of seven common types of adverse events to dynamically measured retroreflection. The main goal of this research was to explore in which way adverse events that occur during the dynamic retroreflection measurement affect the road marking evaluation process. We found out that overall these events account for $2.10 \%$ of the total measured length of road markings. Since retroreflection in this $2.10 \%$ of the measurement is zero or relatively low it may significantly affect the accuracy of the final evaluation of the road markings quality.

Therefore, we developed model (E3) which is able to accurately predict the share of this events based on the total measured length of road markings. The developed model was validated with the new dataset, not previously used in the developing phase, and showed satisfactory accuracy ( $5 \%$ difference of the real values) from which one may conclude that the model is applicable when evaluating the quality of road markings. In other words, developed model may help road authorities to predict the length of adverse events and eliminate them from the results of dynamic measurements in order to accurately evaluate the quality of the marking.

The limitation of this study is that it takes into account only measurement done on the state roads in Croatia which are single carriageway roads. Future modelling work should explore the share of these events on other road types and incorporate a larger array of adverse events not covered here in the Croatian context. 


\section{References}

Andrady, A. L. 1997. Pavement marking materials: Assessing environment-friendly performance. National Cooperative Highway Research Program Report 392, National Academy of Science. USA. 66 p.

Babic, D.; Fiolic, M.; Prusa, P. 2014. Evaluation of road markings retoreflection measuring methods, European Scientific Journal 3: 1857 - 7881. e - ISSN: 1857- 7431.

Benz, R. J.; Pike, A. M.; Kuchangi, S. P.; Brackett, Q. 2009. Serviceable pavement marking retroreflectivity levels: Technical report (Report No. FHWA/TX-09/0-5656-1). Texas Transportation Institute. USA. $150 \mathrm{p}$.

Craig, W. N.; Sitzabee, W. E.; Hummer, J. E.; Rasdorf, W. J. 2007. Impact of line location on pavement marking retroreflectivity degradation, Journal of Public Works Management and Policy 12(2): 431-450. doi: 10.1177/1087724X07308773.

Cuelho, E.; Stephens, J.; McDonald, C. 2003. A review of the performance and costs of contemporary pavement marking systems (ReportNo.FHWA/MT-03-001/8117-17).Western Transportation Institute College of Engineering Montana State University. 31 p.

Dale, M.; Mull, P. E.; William, E.; Sitzabe, P. E. 2012. Paint pavement marking performance prediction model that includes the impacts of snow removal operations, Journal of Transportation Engineering 138(5): 618-624. 10.1061/(ASCE)TE.1943-5436.0000360, 13805618624.

Debaillon, C.; Carlson, P.; He, Y.; Schnell, T.; Aktan, F. 2007. Updates to research on recommended minimum levels for pavement marking retroreflectivity to meet driver night visibility needs (Report No. FHWA-HRT-07-059). The Federal Highway Administration. USA. 46 p.

European Norm. 2009. EN 1436: Materials for road markings-characteristics.

Federal Highways Administration. 1981. Highwaysafetystewardship report. U.S. Department of Transportation. USA. 101 p.
Gibbons, R. B.; Williams, B.; Cottrell, B. 2012. Refinement of drivers' visibility needs during wet night conditions, Transportation Research Record: Journal of the Transportation Research Board 2272: 113-120. doi: 10.3141/2272-13.

Gibbons, R. B.; Hankey, J. 2007. Wet night visibility of pavement markings - dynamic experiment, Transportation Research Record: Journal of the Transportation Research Board 2337: 67-73. doi: 10.3141/2337-09.

Gibbons, R.; Williams, B. 2012. Assessment of the durability of wet night visible pavement markings: Wet visibility project phase IV. Virginia Tech Transportation Institute. USA. 50 p.

Graham, J. R.; Harrold, J. K.; King, E. L. 1996. Pavement markings retroreflectivity requirements for older drivers, Transportation Research Record: Journal of the Transportation Research Board 1529: 65-70. doi: 10.3141/1529-08.

Grosges, T. 2008. Retro-reflection of glass beads for traffic road stripe paint, Optical Materials 30(10): 15491554. doi: 10.1016/j.optmat.2007.09.010.

Loetterle, F. E.; Beck, R. A.; Carlson, J. 2000. Public perception of pavement - marking brightness, Transportation Research Record: Journal of Transportation Research Board 1715: 51-59. doi: 10.3141/1715-08.

Miller, T.R. 1992. Benefit-cost analysis of lane marking, Transportation Research Record: Journal of Transportation Research Board 1334: 38-45.

Migletz, J.; Fish, J. K.; Graham, J. L. 1994. Roadway delineation practices handbook. Graham-Migletz Enterprises. USA. 266 p.

Parker, N. A.; Meja, J. S. M. 2003. Evaluation of the performance of permanent pavement markings, Transportation Research Record: Journal of Transportation Research Board 1824: 123-132. doi: 10.3141/1824-14.

Shahata, K.; Fares, H.; Zayed, T.; Abdelrahman, A.; Chughtai, F. 2008. Condition rating models for sustainable pavement marking. In Proceedings of the

\section{jitte 152}


TRB 87th Annual Meeting Compendium of Papers DVD, Washington, D. C., 8-18.

Sitzabee, W. E.; White, E. D.; Downining, A. W. 2013. Degradation Modeling of polyurea pavement markings, Public Works Management Policy 18(2): 185-199. doi: $10.1177 / 1087724 X 12462831$.

Sitzabee, W.; Hummer, J.; Rasdorf, W. 2009. Pavement marking degradation modeling and analysis, Journal of Infrastructure Systems 15(3): 190-199. doi: 10.1061/ (ASCE)1076-0342(2009)15:3(190).

Technical Terms. 2010. Company Croatian Roads Ltd., Zagreb, Croatia

Tsyganov, A. R.; Machemehl, R. B.; Warrenchuk, N. M.; Wang, Y. 2006. Before-after comparison of edgeline effects on rural two-lane highways. Texas Department of Transportation. USA. 105 p.

Zhang, G.; Hummer, J. E.; Rasdorf, W. 2010. Impact of Bead density on paint pavement marking retroreflectivity, Journal of Transportation Engineering 136(8): 773-781. 10.1061/(ASCE)TE.1943-5436.0000142, 13608773781.

Zwahlen, H.T.; Schnell, T. 2000. Drive eye scanning behavior at night as a function of pavement marking configuration, Transportation Research Record: Journal of the Transportation Research Board 1605: 62-72. doi: 10.3141/1605-08.

Zwahlen, H.T.; Schnell, T. 1997. Minimum in-service retroreflectivity of pavement marking, Transportation Research Record: Journal of the Transportation Research Board 1715: 60-70. doi: 10.3141/1715-09.

\section{Appendix 1}

Coefficients Used for Developing the Models

\begin{tabular}{|c|c|c|c|}
\hline County & $\begin{array}{c}\text { Coefficient } \boldsymbol{k}_{\boldsymbol{i}} \\
\text { for } \mathbf{m o d e l} \boldsymbol{E}_{\boldsymbol{1}}\end{array}$ & $\begin{array}{c}\text { Coefficient } \boldsymbol{k}_{\boldsymbol{i}} \\
\text { for } \text { model } \boldsymbol{E}_{\boldsymbol{2}}\end{array}$ & $\boldsymbol{P}_{\boldsymbol{a}}$ \\
\hline Bjelovar-Bilogora & 0.009 & 0.00814 & 0.09412 \\
\hline Brod-Posavina & 0.01699 & 0.01699 & 0 \\
\hline Dubrovnik-Neretva & 0.05405 & 0.03396 & 0.37169 \\
\hline Istra & 0.0171 & 0.00831 & 0.51403 \\
\hline Karlovac & 0.00905 & 0.00707 & 0.21845 \\
\hline Koprivnica-Križevci & 0.01497 & 0.01102 & 0.26393 \\
\hline Krapina-Zagorje & 0.01593 & 0.01153 & 0.27612 \\
\hline Lika-Senj & 0.00758 & 0.00607 & 0.2 \\
\hline Međimurje & 0.02318 & 0.00826 & 0.64396 \\
\hline Osijek-Baranja & 0.02117 & 0.0046 & 0.78283 \\
\hline Požega-Slavonia & 0.01852 & 0.00915 & 0.50588 \\
\hline Primorje-Gorski Kotar & 0.01788 & 0.01101 & 0.38424 \\
\hline Šibenik-Knin & 0.0154 & 0.01034 & 0.32864 \\
\hline Sisak-Moslavina & 0.03295 & 0.00917 & 0.72178 \\
\hline Split-Dalmatia & 0.03316 & 0.03037 & 0.08394 \\
\hline Varaždin & 0.01556 & 0.00951 & 0.38872 \\
\hline Virovitica-Podravina & 0.0164 & 0.01425 & 0.131 \\
\hline Vukovar-Srijem & 0.02976 & 0.00946 & 0.6822 \\
\hline Zadar & 0.0167 & 0.01461 & 0.12531 \\
\hline Zagreb & 0.01329 & 0.01299 & 0.02273 \\
\hline Weighted Mean Value & $\mathbf{0 . 0 0 2 5 3 9 5}$ & $\mathbf{0 . 0 1 6 5 7 7}$ & $\mathbf{0 . 4 9 8 8 1 8 .}$ \\
\hline
\end{tabular}

